\title{
A filosofia da tecnologia e a formação de professores da educação profissional: algumas reflexões
}

The philosophy of technology and the teachers training in vocational education: some reflections

Leila Cristina Aoyama Barbosa, Escola Técnica Estadual de Rondonópolis, leila.aoyama@gmail.com

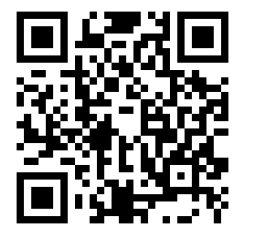

$\mathrm{N}$ esta última década é possível notar mudanças nas políticas educacionais da educação profissional e tecnológica (EPT), que culminaram na expansão da rede federal dessa modalidade, na criação dos Institutos Federais de Educação, Ciência e Tecnologia e na ampliação da oferta de cursos de nível superior tecnológico. Aumentou-se o número de vagas para os cursos técnicos e tecnológicos, ampliou-se o quadro de servidores públicos (professores e técnicos administrativos) dessas instituições, porém notam-se poucas ações para o desenvolvimento de cursos de formação docente específica para atuar nos cursos desta modalidade educacional (OLIVEIRA JÚNIOR, 2008; OLIVEIRA, 2010; PENA 2011).

Seguindo os moldes das universidades para contratação de professores, não há grandes exigências quanto à formação pedagógica desses docentes, visto que, para se ministrarem aulas em um curso de Engenharia, basta ser engenheiro. Desse modo, a discussão sobre a importância do saber pedagógico na identidade docente da EPT é tema já pesquisado por Marques (1996), Oliveira (2006) e Burnier (2006), no entanto ainda cabem novos estudos sobre a formação docente para a educação profissional, objetivando a compreensão de como ocorre o processo formativo e a atuação dos professores nessa modalidade de educação (PENA, 2011).

Vislumbrando para além das preocupações com os saberes pedagógicos que os professores da EPT possuem ou constituíram em formações continuadas, buscar-se-á aqui suscitar uma reflexão sobre os saberes epistemológicos desses indivíduos para o conceito de tecnologia.

Se os cursos em que esses docentes trabalham estão inseridos na modalidade EPT e são regidos por diretrizes curriculares (Parecer CNE/CEB n 16/1999 e n²9/2002) que defendem a qualificação profissional dos estudantes por meio de atividades especializadas, porém não tecnicistas, e sim voltadas para a formação crítica de um cidadão, torna-se importante 
que esses professores consolidem pensamentos sobre o que é técnica, tecnologia e sobre como elas influenciam a vida em sociedade e podem alterar a relação do ser humano com o sistema de produção vigente (mercado de trabalho).

Desse modo, este artigo tem por objetivo apresentar breves reflexões sobre a necessidade da inclusão da filosofia da tecnologia nos cursos de formação continuada de professores da EPT. Para tanto, serão levados em conta aspectos filosóficos e epistemológicos sobre o conceito de tecnologia, difundido por alguns filósofos clássicos e contemporâneos, de modo que este trabalho possa se tornar subsídio para o estudo sobre 0 assunto entre professores, contribuindo com a própria formação docente. Neste espaço reflexivo será apresentada, também, uma pequena revisão de literatura sobre pesquisas já realizadas com a temática "concepções de professores sobre tecnologia", conforme já destacado em parágrafos anteriores, a fim de que se compreenda como essas visões podem interferir no ensino e na atuação dos professores em cursos da EPT.

Trata-se de um ensaio teórico que busca promover a reflexão sobre o assunto. Assim, caracteriza-se pela abordagem qualitativa com a utilização da pesquisa bibliográfica como meio de investigação.

\section{A FORMAÇÃO DE PROFESSORES PARA A EDUCAÇÃO PROFISSIONAL: O QUE HÁ DE CONCRETO NO BRASIL?}

Em 1909, no governo Nilo Peçanha, inicia-se a história dos cursos de educação profissional no Brasil. Com o intuito de fornecer um ofício aos mais desvalidos economicamente, foi criada, por meio do decreto n. ${ }^{0}$ 7.566/1909, as Escolas de Aprendizes Artífices. Voltados, inicialmente, para a formação de novos trabalhadores de artes manuais (marceneiros, funileiros, alfaiates, sapateiros, entre outros), os "mestres" - professores que ensinavam o ofício aos aprendizes - eram pessoas que já trabalhavam naquela função e demonstravam capacidade ao ofício; portanto não se exigia uma comprovação do saber teórico deste profissional. Também este assunto nem era preocupação das legislações; pois, o decreto de criação destas escolas contemplava os deveres do professor, "incluindo cuidados com ferramentas e utensílios, passando pelos apontamentos e registros de frequência e chegando às normas de obediência ao diretor, mas nem um único artigo foi dedicado à formação desse docente" (OLIVEIRA JÚNIOR, 2008, p. 04).

O primeiro registro histórico de um curso de formação docente para educação profissional é datado em 1917. Foi um curso oferecido pela Escola Normal de Artes e Ofícios Wenceslau Brás, no Rio de Janeiro, que atendia professores tanto do ensino primário como da educação profissional. Outras informações do histórico sobre a formação de professores para a EPT são relatadas por Machado (2008), que, a partir do levantamento de toda a legislação pertinente ao tema, verifica que essas formações constituem-se de iniciativas esparsas e experiências isoladas.

Em outro estudo, Oliveira (2010), analisando a Lei de Diretrizes e Bases da Educação Nacional (LDB) atual e os últimos Decretos e Pareceres pertinentes ao tema, evidencia a falta de diretrizes sobre formação docente para atuação na EPT.

Comparando os dois últimos decretos que regulamentam os artigos da LDB referentes à educação profissional (Decreto n. ${ }^{\circ}$ 2.208/1997 e Decreto n. ${ }^{\circ}$ 5.154/2004), observa-se a não linearidade das políticas públicas quanto ao tema em questão. 0 primeiro decreto citado previa, em seu artigo 09, a preparação dos professores, instrutores e monitores da educação profissional ao magistério por meio de cursos regulares de licenciatura ou de programas especiais de formação pedagógica. Já o decreto atualmente vigente despreza a questão da formação desses docentes, não tratando sobre o assunto. Desse modo, apesar de o tema estar contemplado na resolução $n^{\circ}$ 02/1997 do Conselho Nacional de Educação (CNE), que dispõe sobre os programas especiais de formação pedagógica de docentes, cada instituição de EPT decide como esse processo formativo deve ocorrer.

Há, hoje, ofertas formativas diversificadas de formação de docentes para este campo, mas são muito reduzidas considerando o potencial de demanda e nem sempre atendem a todos os perfis de entrada dos candidatos. Essas ofertas são constituídas por programas especiais, cursos de pós-graduação, formação em serviço e formação a distância (MACHADO, 2008, p. 14).

É preciso esclarecer, porém, que esse processo formativo deve ser mais do que a discussão de questões didáticas e pedagógicas.

\begin{abstract}
A formação e a capacitação devem, portanto, ir além da aquisição de técnicas didáticas de transmissão de conteúdos para os professores e de técnicas de gestão para os dirigentes. Evidentemente, esses aspectos continuarão sendo importantes, mas o objetivo macro é mais ambicioso e deve privilegiar a formação no âmbito das políticas públicas do país, principalmente as educacionais, numa perspectiva de superação do modelo de desenvolvimento socioeconômico vigente, de modo que se deve priorizar mais o ser humano do que, simplesmente, as relações de mercado e o fortalecimento da economia (MOURA, 2008, p. 30).
\end{abstract}

Corroborando com a ideia de Moura (2008), entendemos que o estudo da filosofia da tecnologia pode contribuir para o alcance do objetivo macro proposto pelo autor, pois a reflexão 
dos diversos conceitos de tecnologia podem auxiliar os professores a compreender a realidade e o modo como a sociedade vem se relacionando com a tecnologia.

É próprio do ensinar-aprender tecnologia e, portanto, da docência na educação profissional tratar da intervenção humana na reorganização do mundo físico e social e das contradições inerentes a esses processos, exigindo discutir questões relacionadas às necessidades sociais e às alternativas tecnológicas (MACHADO, 2008, p. 16).

Sendo assim, a próxima seção trará a exposição de algumas ideias da filosofia da tecnologia, seus filósofos e conceitos, a fim de subsidiar a reflexão sobre as benesses da inclusão desse conteúdo no currículo das formações continuadas de professores para a educação profissional.

\section{0 conceito de tecnologia: aspectos filosóficos}

Esta seção apresentará brevemente o conceito de tecnologia difundido por alguns filósofos. Não é intuito aprofundar o tema, visto que se trata de um assunto complexo e vasto. Além disso, este é um primeiro trabalho que busca identificar indícios de como a filosofia da tecnologia pode se apresentar na formação continuada para professores da EPT. Trata-se de um exercício voltado à reflexão das práticas pedagógicas e à práxis da própria autora, professora da educação profissional há sete anos que, recentemente, iniciou estudos nesta área do conhecimento.

A Filosofia da Tecnologia é uma disciplina atualmente presente no currículo de cursos de graduação de Filosofia em universidades brasileiras. Entretanto, parece não despertar tanto interesse entre os acadêmicos devido ao seu perfil intelectual mais voltado às leituras humanísticas do que às "técnicas" (CUPANI, 2011). Em outras graduações, como as Engenharias, o tratar desse assunto está relacionado às disciplinas sobre Ciência, Tecnologia e Sociedade (CTS), porém, quando buscamos compreender o que é refletir sobre a tecnologia, concluímos que, por se tratar de um assunto de participação democrática, não deveria estar restrito a grupos específicos. Por meio de discussões sobre tecnologia surgem indagações do tipo:

\footnotetext{
É melhor dispor de ar condicionado ou repensar a arquitetura e a relação do homem com o meio ambiente? Deslocar-se de carro, embora sendo uma maneira mais cômoda e veloz de encurtar distâncias, não se converte em um hábito que quase elimina o exercício corporal, provocando doenças? 0 uso da internet, instrumento fantástico de informação e comunicação, não ameaça reduzir o conhecimento a acúmulo de dados e permitir que nossa vida pessoal seja controlada? De modo
}

geral, é melhor ou pior, em algum sentido, a vida numa sociedade tecnológica? 0 que se ganha em eficiência, velocidade, produtividade, novidade, não se perde acaso em espontaneidade, serenidade, qualidade, tradição? (CUPANI, 2011, p. 12)

Não há dúvidas de que o aparato tecnológico transforma a vida em sociedade. Mas o que vem a ser a tecnologia? Trata-se de uma aplicação do conhecimento científico? É uma entidade de vida própria que dita as regras do mundo atual?

Dentre tantos filósofos que tratam da temática, foram selecionados cinco deles, de épocas diferentes e pensamentos, às vezes, divergentes: José Ortega y Gasset (1883-1955), Jacques Ellul (1912-1994), Mário Bunge (1919-), Albert Borgmann (1937-) e Andrew Feenberg (1943-). A seguir serão apresentadas, resumidamente, as ideias desses estudiosos, baseadas em leituras de Cupani $(2004,2011)$.

\section{José Ortega y Gasset: uma REFLEXÃO SOBRE A TÉCNICA}

O ensaio filosófico de Ortega y Gasset, Meditacion de la técnica (1939), é um dos primeiros textos a refletir sobre o papel da técnica. Em tempos em que ainda não havia a presença da tecnologia como a conhecemos, o espanhol descreve brilhantemente sobre a técnica e como ela transformou a vida humana: um indício do que estaria por vir com a revolução das máquinas.

Adotando uma perspectiva ontológica para abordar o assunto, Ortega y Gasset entende que a técnica encontra-se vinculada à vida do ser humano. A partir do uso de técnicas, 0 homem pôde suprir suas necessidades, no entanto

[...] a técnica não é o que o homem faz para satisfazer suas necessidades. [... ] A técnica é a reforma da natureza, dessa natureza que nos faz necessitados e carentes, uma reforma num sentido tal que as necessidades fiquem, tanto quanto possível, anuladas por deixar de ser um problema a sua satisfação (ORTEGA Y GASSET, 1965, p. 21 apud CUPANI, 2011, p. 33).

E, desse modo, as técnicas foram evoluindo com a vida do ser humano, e o supérfluo surgiu, pois o homem não quer somente viver; ele quer viver bem (a necessidade das necessidades).

Para o homem, viver é, desde logo, e antes de qualquer outra coisa, esforçar-se para que haja o que ainda não há: ou seja, ele mesmo, aproveitando para isso o que há; em soma, [viver] é produção. Com isto quero dizer que a vida não é fundamentalmente, como tantos séculos acreditaram, contemplação, pensamento, teoria. Não; ela é produção, fabricação, e 
apenas porque estas últimas o exigem (portanto, depois e não antes) ela é pensamento, teoria e ciência (ORTEGA Y GASSET, 1965, p. 46 apud CUPANI, 2011, p. 34).

Por essa razão, o mundo apresenta-se ao ser humano como matéria-prima. Porém a atitude técnica não é uma entidade independente ou direcionada, nem um fim em si mesma, mas a condição para que o homem possa ser ele mesmo.

Assim, analisando o homem no decorrer dos tempos, Ortega y Gasset classifica, em três, os estágios da relação do ser humano com as atitudes técnicas: a técnica do acaso (técnica vista como algo da natureza), a técnica do artesão (consciência de que o ser humano possui aptidões e crença de que essas eram características natas) e a técnica do técnico (enxergam o homem como inventor e produtor de máquinas).

Apesar de ter feito essa análise até a década de 1960, a classificação do filósofo espanhol é válida, pois ele aponta que, neste terceiro estágio, se criou a ilusão de uma técnica mais firme e independente por influência da ciência, o que se configura como uma concepção da tecnologia. E o filósofo ainda alertava:

[...] a técnica, ao aparecer por um lado como capacidade em princípio ilimitada, faz com que para o homem, decidido a viver da fé na técnica e só nela, a vida se torne vazia. Porque ser técnico e apenas técnico é poder ser tudo, e, por conseguinte, não ser nada determinado. Por estar cheia de possibilidades, a técnica é mera forma oca - como a lógica mais formalista -, é incapaz de determinar o conteúdo da vida. Por isso, estes anos em que vivemos, os mais intensamente técnicos que já houve na história humana, são os mais vazios (ORTEGA Y GASSET, 1965, p. 81 apud CUPANI, 2011, p. 39).

Mal sabia Ortega y Gasset do que estava por vir no novo século.

\section{JACQUES ELLUL: O DETERMINISMO TECNOLÓGICO}

Jacques Ellul é um francês polivalente que acumula as formações de sociólogo, filósofo e teólogo. Seu livro mais conhecido, "A técnica ou o desafio do século", foi escrito em 1954 e já trazia reflexões e comparações sobre as primeiras técnicas (operações técnicas) e a tecnologia (fenômeno técnico). Ellul não utiliza o termo tecnologia. Para ele tudo se trata de técnica que foi se alterando no decorrer da história humana.

O filósofo francês defende a tese de que o fenômeno técnico constitui uma realidade autônoma. Ao analisar os procedimentos das primeiras técnicas, assim como Ortega y Gasset, Ellul identifica que o homem as utilizava para melhorar seu bem viver, porém que ela ganhou proporções ilimitadas: tornou-se racional, artificial, autômata, universal, está centrada na eficiência e torna o progresso autodirigido (ELLUL, 1964 apud CUPANI, 2011), entretanto sem direção definida.

\begin{abstract}
A técnica [...] não persegue nenhum fim, declarado ou não. Ela evolui de uma maneira puramente causal: a combinação de elementos precedentes fornece os novos elementos técnicos. Não há propósito ou plano que esteja sendo progressivamente realizado. Não há nem sequer uma tendência para fins humanos. Estamos lidando com um fenômeno cego para o futuro, em um domínio de causalidade integral (ELLUL, 1964, p. 97 apud CUPANI, 2011, p. 211).
\end{abstract}

E nesse futuro cego, Ellul salienta que o fenômeno técnico foi modificando a vida do ser humano, de modo que transformou sua capacidade de reflexão em reflexo. Apesar desta causalidade integral da técnica, não há dúvidas de que ela substitui valores de sociedades tradicionais, acaba por destruir culturas precedentes e cria uma nova moralidade à qual o homem se adapta.

\section{MÁrio BUnge: a FILOSOFIA ANALÍtica DA TECNOLOGIA}

Este filósofo argentino analisa conceitualmente os termos técnica e tecnologia e acredita que a diferença entre ambos encontra-se no pensamento científico. Enquanto a primeira baseia-se do saber vulgar, a segunda serve-se do saber científico para a produção tecnológica. "A tecnologia pode ser definida como 'o campo de conhecimento relativo ao desenho de artefatos e à planificação da sua realização, operação, ajustamento, manutenção e monitoramento, à luz de conhecimento científico'" (BUNGE, 1985b, p. 231 apud CUPANI, 2011, p. 95). No entanto, Bunge também diferencia ciência aplicada de tecnologia. Para ele existem os três conceitos: ciência básica (saber puro), ciência aplicada (saber útil) e a tecnologia (busca de solução aos problemas práticos a partir de recursos científicos); os dois primeiros orientam-se inerentemente ao saber, enquanto a tecnologia está orientada ao fazer.

Bunge dedica-se fortemente a estudar sobre o comportamento do tecnólogo frente ao seu trabalho e às questões que a tecnologia envolve, como, por exemplo: epistemologicamente, ao afirmar que "ao tecnólogo interessa o conhecimento como um meio de ação, não como algo de valor inerente" (CUPANI, 2011, p. 110); axiologicamente, ao indagar "que indicadores de valores tecnológicos são mais fidedignos: a razão benefício-custo, o tempo economizado, ou outros?" (CUPANI, 2011, p. 112); e eticamente, ao apontar que a tecnologia não é neutra, mas, no mínimo, ambivalente (BUNGE, 1985a). 
0 filósofo também apresenta opiniões críticas, como a afirmação de que "o tecnólogo deve, por definição, servir aos interesses de quem determina o objetivo a ser alcançado" (CUPANI, 2011, p. 101), porém que "eles têm o dever de negarem-se a colaborar em projetos eticamente objetáveis" (Ibid, p. 115), e outras polêmicas, como sua posição iluminista de crer que "toda tradição equivale a atraso e de que toda cultura não científica é de algum modo defeituosa" (Ibid, p. 119).

\section{Albert Borgmann: a filosofia FENOMENOLÓGICA DA TECNOLOGIA}

Utilizando-se de um enfoque fenomenológico, que se esforça para descrever o fenômeno da tecnologia e os elementos que se manifestam dela, Borgmann, diferentemente de Bunge, não compreende a tecnologia como forma de técnica mais evoluída por conta de sua associação com a ciência.

[...] na técnica tradicional toda relação meio-fim estava inserida em um contexto (social, cultural, ecológico), na tecnologia a relação meio-fim vale universalmente, com independência dos contextos concretos. Enquanto a lareira tradicional, ainda que fosse um meio para aquecer o lar, estava inserida na trama de relações entre os membros da família, supunha o trabalho necessário para acendê-la e mantê-la e incentivava a reunião da família e o cultivo dos costumes, o aquecedor moderno se reduz à sua função de fornecer calor, não importa para quem, nem em quais circunstâncias (BORGMANN, 1984 apud CUPANI, 2004, p. 302).

Para esse filósofo, a tecnologia tornou-se um paradigma intrínseco à vida cotidiana, representando um modo de vida próprio da Modernidade. No entanto, também discorda da autonomia tecnológica proposta por Jacques Ellul. 0 homem não é simplesmente arrastado pela tecnologia, porém o que existe é uma cumplicidade do homem com ela, isto é, o ser humano é responsável pela manutenção do modo de vida tecnológico, que tanto nos fascina e nos fornece status. Teses como esta, de cunho fenomenológico, recebem crítica por parte de Cupani (2011), por apenas compreender o fenômeno da tecnologia e não explicá-lo. Borgmann "subestima o peso dos fatores e circunstâncias sociais, que, por uma parte, modelam a vida e a consciência das pessoas" (Ibid, p. 150).

\section{Andrew Feenberg: a perspectiva CRÍTICA DA FILOSOFIA DA TECNOLOGIA}

Feenberg escreveu seus postulados no último quinquênio. Adepto da Escola de Frankfurt, ele analisa a perspectiva contemporânea da tecnologia.
A tecnologia, concorda Feenberg, é um fenômeno tipicamente moderno. Mais ainda, ela constitui a "estrutura material" da Modernidade. Mas a tecnologia, no argumento do autor, não é um mero instrumento neutro, pois ela encarna valores antidemocráticos provenientes da sua vinculação com o capitalismo e manifestos numa cultura de empresários, que enxerga o mundo em termos de controle, eficiência (medida pelo proveito alcançado) e recursos. Os valores e interesses das classes dominantes estão inscritos no próprio desenho dos procedimentos e máquinas, bem como nas decisões que os originam e mantêm. Por outro lado, a tecnologia não constitui uma entidade autônoma nem um "destino" (CUPANI, 2004, p. 508).

Este filósofo americano, atualmente habitante do Canadá, apresenta quatro classificações do conceito de tecnologia, que trazem o pensamento de outros filósofos e sua própria tese (FEENBERG, 2003).

- Determinismo - Segundo esta visão, amplamente sustentada nas ciências sociais desde Marx, 0 avanço tecnológico é a força motriz da história. Para os deterministas, a tecnologia não é humanamente controlada, mas, ao contrário, é ela quem controla os humanos, isto é, molda a sociedade pelas exigências de eficiência e progresso.

- Instrumentalismo - A tecnologia é vislumbrada simplesmente como uma ferramenta ou instrumento da espécie humana por meio do qual satisfazemos nossas necessidades. Esta visão corresponde à fé liberal no progresso e o otimismo da presença da tecnologia na sociedade.

- Substantivismo - Em contraste às duas visões anteriormente citadas, o substantivismo enxerga a tecnologia como carregada de valores e são estes valores escolhidos por uma sociedade que a moldam. A teoria substantiva tem caráter crítico e entende a autonomia da tecnologia como malévola e ameaçadora.

- Teoria crítica - Esta teoria reconhece as consequências pessimistas do desenvolvimento tecnológico defendidas pelo substantivismo, mas ainda vislumbra na tecnologia uma promessa para aumentar a liberdade. Segundo Feenberg, o problema não está na tecnologia como tal, mas na ineficiência humana em criar instituições adequadas para o controle dessa tecnologia.

Assim, o filósofo aponta que o poder tecnológico tornou-se a principal forma de poder no mundo atual e que uma solução para a domesticação da tecnologia e mudança da direção que 
ela vem tomando seria submetê-la a um processo mais democrático em seu projeto e desenvolvimento.

\section{AS CONCEPÇÕES DOCENTES SOBRE TECNOLOGIA: A NECESSIDADE DA FORMAÇÃO CONTINUADA EM FILOSOFIA DA TECNOLOGIA}

Em uma rápida busca por investigações brasileiras sobre as concepções de tecnologia que professores da educação básica ou do ensino técnico possuem, foram selecionados seis trabalhos a fim de compreender o perfil docente quanto ao tema tecnologia: dois retratando a realidade da educação profissional (RIBEIRO \& OLIVEIRA, 2009; BREMER, 2006), outros dois trabalhos, cujos sujeitos de pesquisa foram professores da área de Ciências e Matemática do ensino médio (RICARDO et al., 2007; FIRME \& AMARAL, 2008), e mais dois contendo concepções sobre ciência, tecnologia e sociedade de professores da educação básica (AULER \& DELIZOICOV, 2006; MIRANDA \& FREITAS, 2008).

Nota-se que cada um deles apresenta categorias de análise diferenciadas, algumas delas baseadas em estudiosos da tecnologia, porém somente um deles é baseado em conceitos filosóficos. Entretanto, todos apontam para resultados semeIhantes ao identificarem visões acríticas e concepções equivocadas dos professores sobre tecnologia.

Auler \& Delizoicov (2006) indicam que há uma compreensão confusa e ambígua dos professores sobre a não neutralidade da Ciência/Tecnologia, de modo que há o endosso ao modelo de decisões tecnocráticas, isto é, a não concordância com a democratização das decisões sobre tecnologias, conforme defendem Borgmann e Feenberg. Além disso, os professores investigados apresentaram passividade diante do desenvolvimento científico-tecnológico (concepção determinista de tecnologia, conforme Ellul e classificação de Feenberg), porém mostraramse contrários à perspectiva salvacionista atribuída à Ciência/ Tecnologia, indicando alguma visão crítica sobre a temática.

Já a pesquisa realizada por Miranda \& Freitas (2008) apontou que a maior parte dos professores entende a tecnologia como uma aplicação da ciência, indicando uma concepção, denominada por Feenberg e outros filósofos instrumentalista. Esse pensamento vem acompanhado da ideia de superioridade hierárquica da ciência à tecnologia. Os professores apresentaram ainda uma concepção substantivista de tecnologia por entendê-la como fundamento da prática social.

Por sua vez, as investigações de Ricardo et al. (2007) e Firme \& Amaral (2008) diagnosticaram que professores da área de ciências do ensino médio possuem concepções intrumentalistas de tecnologia devido à crença de que esta se trata de uma aplicação dos conhecimentos científicos e que a ciência sempre a precede, visão que se assemelha ao conceito disseminado por Mário Bunge.

Esses resultados confirmaram-se nos outros dois estudos desenvolvidos com professores da educação profissional. Ribeiro \& Oliveira (2009) analisaram as concepções de professores do curso Técnico em Óptica, de Minas Gerais, e as identificaram como intrumentalista, voltada para a eficiência e produtividade, e também determinista. Desse modo as autoras indicam a necessidade de cursos de formação continuada para professores, não somente para saberem lidar com a dimensão instrumental, mas, principalmente, para saberem discutir e agir em relação ao fenômeno tecnológico nos cursos técnicos.

Já a pesquisa de Bremer (2006), que apresentou o maior número de sujeitos investigados por abranger toda a rede pública estadual de educação profissional do Paraná, verificou o caráter polissêmico da tecnologia, pois os professores consideram-na como: conhecimento, técnica, aplicação da técnica e do conhecimento, instrumento e ferramenta, desenvolvimento e inovação, informação e informatização, trabalho e processo produtivo. Entretanto, observando as definições dadas pelos docentes, de acordo com a filosofia da tecnologia, notase que todas essas categorias elucidadas indicam uma concepção instrumentalista de tecnologia, pois colocam sempre a técnica e os artefatos tecnológicos a serviço do ser humano.

Assim, esse pequeno levantamento de pesquisas brasileiras sobre concepções docentes de tecnologia indica uma visão instrumentalista e determinista dos educadores - fato este que dificulta uma mudança no pensamento coletivo sobre tecnologia e fortalece os ideais capitalistas, pois "a força do discurso determinista tecnológico na sociedade industrial é diretamente proporcional aos processos de alienação advindos das desiguais relações sociais de produção" (LIMA FILHO \& QUELUZ, 2005, p. 20).

Uma visão instrumentalista é antropocêntrica e reduz a tecnologia ao mero papel de ferramenta ao ser humano. Além disso, uma visão determinista torna-se fatal por considerar os sistemas tecnológicos como autônomos e ignorar a possibilidade de o ser humano tomar decisões sobre o processo de desenvolvimento tecnológico, isto é, desconsiderar os valores que a tecnologia carrega.

Alguns professores podem ir modificando suas concepções de tecnologia conforme suas experiências pessoais e profissionais, porém Machado (2008) ressalta que o caráter operatório da tecnologia pode ganhar representações diversas: às vezes, benéficas para o senso crítico; outras, de sentidos atribuíveis à ideia de eficácia e de sucesso. Daí surge a necessidade de uma formação consistente, fundamentada e crítica.

Conforme destacado em seções anteriores, a formação continuada de professores para a educação profissional apresenta 
suas especificidades e dificuldades por conta da amplitude de áreas do conhecimento e de profissionais que se tornam docentes dessa modalidade educacional. Desse modo, torna-se necessário oportunizar aos professores momentos para discutir suas práticas docentes, não somente as voltadas para a didática, mas, principalmente, aquelas que contemplem a formação cidadã dos alunos, como a ética, a sociologia e também a filosofia da tecnologia. Se queremos formar profissionais técnicos e tecnólogos que reconheçam que seu papel frente ao mercado de trabalho é muito mais do que mão de obra e que, diferentemente do apontamento de Bunge (1985a), não são servos do capitalismo, é preciso que o professor possua concepções críticas e argumentações embasadas para transpor as concepções vigentes da sociedade.

\section{ReflexÕEs Finals}

A educação profissional tem a tecnologia como objeto de estudo e espaço de intervenção (MACHADO, 2008), porém nem sempre os professores dessa modalidade educacional têm consciência de sua função de mediadores do conhecimento para além da racionalidade técnica.

Todos os filósofos expostos neste ensaio concordam que o modo como o ser humano se relacionou com as técnicas e com a tecnologia levou-o a mudanças drásticas na vida em sociedade. Alguns possuem uma visão mais pessimista, apontando a alienação humana como consequência do desenvolvimento tecnológico, como Ellul e Ortega y Gasset; outros, como Borgmann, Bunge e Feenberg, entendem que foram as atitudes do ser humano que implantaram o modelo tecnológico vigente. Sendo assim, a adoção de novas posturas será capaz de transformá-la.

A busca por essa transformação começa com diálogos em salas de aulas entre seus atores (estudantes e professores). Nas modalidades de ensino da educação básica ou no nível superior é possivel levar reflexões sobre qual é a tecnologia que queremos desenvolver: por quê? como? para quem? Entretanto, os cursos de educação profissional tornam-se espaços em que esses diálogos deveriam ocorrer mais facilmente, pois os estudantes lidam diretamente com a tecnologia em suas diversas interfaces.

Desse modo, o desenvolvimento de cursos de formação continuada para professores da educação profissional que enfatizem a filosofia da tecnologia pode desencadear o processo de alteração de concepções fatalistas sobre a temática, primeiro dos docentes e comunidade escolar e, em seguida, da sociedade em geral, para uma visão mais crítica e que oportunize a participação popular nas decisões tecnológicas.

\section{REFERÊNCIAS}

AULER, D.; DELIZOICOV, D. Ciência-Tecnologia-Sociedade: relações estabelecidas por professores de ciências. Revista Electrónica de Enseñanza de lãs Ciencias, v. 05, n. 02, p. 337-355, 2006. Disponível em: <http://www.saum.uvigo.es/ reec/volumenes/volumen5/ART8_Vol5_N2.pdf $>$. Acesso em: 18 jul. 2012.

BORGMANN, A. Technology and contemporary life: a philosophical inquiry. Chicago: The University Chicago Press, 1984.

BRASIL. Parecer da Câmara de Educação Básica (CEB) $n^{\circ} 16$, de 25 de novembro de 1999. Poder executivo. Trata das Diretrizes Curriculares Nacionais para a Educação Profissional de Nível Técnico. Brasília, 1999.

Parecer da Câmara de Educação Básica (CEB) n 29, de 03 de dezembro de 2002. Poder executivo. Trata das Diretrizes Curriculares Nacionais no Nível de Tecnolólogo. Brasília, 2002.

BREMER, M. A. S. Trabalho, Tecnologia e Competências: concepções e práticas dos professores da Educação Profissional. In: Ensaios Educacionais. 1. ed. Curitiba: Secretaria Estadual de Educação, p. 153-165, 2006.

BUNGE, M. Seudociencia y ideologia. Madrid: Alianza, 1985b.

Racionalidad y realismo. Madrid: Alianza, 1985a.

BURNIER, S. L . A docência na educação profissional. In: Reunião Anual da ANPED, 29, Caxambu. Anais... Caxambu: ANPED, 2006. Disponivel em: <http://www.anped.org.br/ reunioes/29ra/trabalhos/trabalho/GT08-1838-Res.pdf>. Acesso em: 05 ago. 2012.

CUPANI, A. Filosofia da tecnologia: um convite. Florianópolis: Editora da UFSC, 2011.

ELLUL, J. The technological society. New York: Vintage Books, 1964.

FEENBERG, A. O que é filosofia da tecnologia? Conferência, University of Komaba/Japão, jun. 2003. Tradução de Agustín Apaza, Disponível em: <http://www.sfu. ca/ andrewf/oquee. htm>. Acesso em: 22 jun. 2012.

FIRME, R. N.; AMARAL, E. M. R. do. Concepções de 
professores de química sobre ciência, tecnologia, sociedade e suas inter-relações: um estudo preliminar para o desenvolvimento das abordagens CTS em sala de aula. Ciência \& Educação [on-line], Bauru, v. 14, n. 2, p. 251-269, 2008. Disponivel em: <http://www.scielo.br/pdf/ciedu/v14n2/ a05v14n2.pdf>. Acesso em: 19 jul. 2012.

LIMA FILHO, D. L.; QUELUZ, G. L. A tecnologia e a educação tecnológica: elementos para uma sistematização conceitual. Educação \& Tecnologia, Belo Horizonte, v. 10, n. 01, p. 19-28, 2005

MACHADO, L. R. de S. Diferenciais inovadores na formação de professores para a educação profissional. Revista Brasileira da Educação Profissional e Tecnológica, Brasília, v.1, n.1, p. 08-22, jun. 2008.

MARQUES, M. O. A formação do profissional da educação. ljuí: Editora Unijuí, 1996.

MIRANDA, E. M.; FREITAS, D. de. A compreensão dos professores sobre as interações CTS evidenciadas pelo questionário VOSTS e entrevista. Alexandria, Florianópolis, v.1, n.3, p.7999, nov. 2008. Disponível em: <http://alexandria.ppgect. ufsc.br/files/2012/04/ELISANGELA-MATIAS-MIRANDADENISE-DE-FREITAS.pdf>. Acesso em 19 jul. 2012.

MOURA, D. H. A formação de docentes para a educação profissional e tecnológica. Revista Brasileira da Educação Profissional e Tecnológica, Brasília, v.1, n.1, p. 23-38, jun. 2008.

OLIVEIRA JÚNIOR, W. A formação do professor para a educação profissional de nível médio: tensões e (in)tenções. In: SEMINÁRIO NACIONAL DE EDUCAÇÃO PROFISSIONAL E TECNOLÓGICA, 01, Belo Horizonte. Anais... Belo Horizonte: CEFET/MG, 2008. Disponível em: <http://www.senept. cefetmg.br/galerias/Arquivos_senept/anais/terca_tema3/ TerxaTema3 Artigo2.pdf>. Acesso em: 18 jul. 2012.

OLIVEIRA, M. R. N. S. de. A formação de professores para a educação profissional. In: DALBEN, A. L.; DINIZ, J.; LEAL, L.; SANTOS, L. (Org.). Coleção Didática e Prática de Ensino. Belo Horizonte: Autêntica, 2010

Formação e profissionalização dos professores do ensino técnico. Educação e Tecnologia, Belo Horizonte, v. 11, n. 02, p. 03-09, jul./dez. 2006.

ORTEGA Y GASSET, J. Meditación de la técnica.Madrid: Espasa-calpe, 1965.
PENA, G. A. C. Formação docente e aprendizagem da docência: um olhar sobre a educação profissional. Educação em Perspectiva, Viçosa, v. 2, n. 1, p. 98-118, jan./jun. 2011.

RIBEIRO, E. R.; OLIVEIRA, M. R. N.S. Concepções de tecnologia no âmbito da formação e na práxis do técnico óptico. In: simpósio sobre Trabalho e Educação, 5, Belo Horizonte. Anais... Belo Horizonte: UFMG, 2009. Disponível em: $<$ www.fae.ufmg.br/gestrado/ files/concdetecno.pdf>. Acesso em: 18 jul. 2012.

RICARDO, E. C.; CUSTÓDIO, J. F.; REZENDE JUNIOR, M. F. A tecnologia como referência dos saberes escolares: perspectivas teóricas e concepções dos professores. Revista Brasileira de Ensino de Física, Porto Alegre, v. 29, n. 1, p. 135-147, mar. 2007. Disponível em: <http://www.sbfisica.org.br/ rbef/ pdf/060701.pdf>. Acesso em: 18 jul. 2012. 